\title{
Classification of progressive massive fibrosis of coalminers by type of radiographic appearance
}

\author{
C A SOUTAR AND H P R COLLINS
}

\author{
From the Institute of Occupational Medicine, Edinburgh EH8 9SU, UK
}

\begin{abstract}
In a pilot study the chest radiographic appearances of 112 coalminers who developed progressive massive fibrosis (PMF) over an 11 year period have been classified into six types based on the appearances of the large radiographic opacities. The most common type of PMF was one or more large shadows of homogeneous radiodensity. Less common types included markedly rounded shadows usually less than $3 \mathrm{~cm}$ in diameter, non-homogeneous shadows appearing to consist of conglomerations of small rounded opacities, and condensations of linear or streaky shadows. Good reproducibility by one reader between two readings were obtained. The lifetime exposures to mixed respirable coalmine dust, and to its quartz component, of these 112 men were compared with those of control subjects matched for age and starting category of simple pneumoconiosis but without PMF. Overall, the men with PMF had been exposed to more mixed dust than controls, confirming that one of the reasons some men with simple pneumoconiosis develop PMF is that they have inhaled more dust than others. Eleven of the 112 cases had large opacities that were not homogeneous and appeared to consist of conglomerations of " $r$ " type small rounded opacities. The average quartz exposures of these men were much higher than in control subjects, suggesting that in this type of PMF quartz was an important causative factor.
\end{abstract}

Progressive massive fibrosis (PMF) of coalminers is known to be related to exposure to respirable dust, ${ }^{1}$ and to be more likely to develop in men who have simple pneumoconiosis. ${ }^{2}$ Recent evidence has indicated that PMF associated with unusually rapid progression of simple pneumoconiosis is in some cases related to high proportions of quartz in the dust to which men have been exposed, ${ }^{3}$ but apart from this it has not been clear why some men with simple pneumoconiosis develop PMF and others do not.

Pathological studies ${ }^{4-6}$ have indicated that more than one type of PMF may be recognised, and that these types of PMF are associated with differing amounts of coal and quartz dust retained in the lungs. ${ }^{7-9}$ Possibly the recognition of different types of PMF classified by the chest radiographic appearances would enable a more clear demonstration of the relation between PMF and exposure to mixed respirable coalmine dust and its component minerals to be made.

A recent study of a group of miners who worked

Received 22 August 1983

Accepted 26 September 1983 in the British coal industry in the 1950 s, and who were re-examined 22 or more years later, identified a subset of men who had developed PMF, and the opportunity has been taken to describe the differing types of radiographic appearances of PMF in some of these men and to examine the reproducibility of these readings. Individual lifetime exposures to mixed respirable coalmine dust and its quartz component in men with these types of PMF have been compared with the exposures of control subjects in order to seek evidence that such a radiological classification might be of value.

\section{Subjects and methods}

Men were selected for study from the records of the National Coal Board's Pneumoconiosis Field Research. A sample of men who had first been examined while working in selected collieries in Britain in the 1950s were followed up 22 or more years later, whether or not they were still working in the industry. In ten of these collieries measurements of dust concentrations and regular medical surveys had continued throughout the 22 year period. The cases and controls for the present study have been drawn 
from 2346 men with adequate data at these ten collieries who were examined at follow up and also at a medical survey occurring about 11 years previously, and whose chest radiographs did not show PMF at this earlier survey.

Of these men, 157 were found to have PMF at the time of the follow up examination, as defined by the majority verdict on the presence of large opacities in the chest radiograph by a panel of five readers. This panel of readers, four of whom were not medically qualified, were trained ${ }^{10}$ in the interpretation of the appearances of chest radiographs according to the ILO U/C classification," and had recorded their classifications of all follow up radiographs presented to them in random sequence. The presence or absence of PMF at the time of the medical survey 11 years previously was based on an agreed classification (definitive reading ${ }^{12}$ ) on the ILO scale $^{13}$ by two or three medically qualified readers experienced in interpreting the appearances of pneumoconiosis. These readings were also used to define the category of simple pneumoconiosis at that time, and for the purpose of selecting control subjects.

For comparisons of dust exposures, these 157 men with PMF at follow up were compared with controls without PMF (defined by majority verdict) drawn from the remainder of the 2346 men. These men were matched to the cases by age in intervals of five years, and since we wished to allow for the known influence of simple pneumoconiosis in predisposing to PMF, by three categories of simple pneumoconiosis (categories $0 ; 1$; and 2 and 3 combined). Three controls were selected for each case. Men were not matched by colliery.

It was possible to match 138 of the cases satisfactorily but the radiographs of six of these were not available at the time of the study. Identification of men with PMF at follow up had been by the panel of self trained readers, who as required by the ILO $\mathrm{U} / \mathrm{C}$ classification ${ }^{11}$ recorded the presence of large opacities without regard to the clinical diagnosis. During the subsequent re-examination of these radiographs by one of us (CAS) it became apparent that 20 of them showed appearances characteristic of other diseases such as tuberculosis; they were excluded from the study. The analysis was therefore confined to 112 men whose radiographs appeared to show large opacities characteristic of PMF of coalminers and 336 controls.

One of us (CAS) believed that he could classify the appearances of PMF into six distinctive types. The follow up chest radiographs were examined in two separate readings each in random order, and the presence of these types of PMF were recorded. Several radiographs appeared to show more than one type, but in the second reading an effort was made to record, where feasible, only the predominant type of appearance. Previous radiographs were examined only if disease other than pneumoconiosis was suspected. The types of PMF were characterised as follows. (See also the figure.)

(1) The large opacities of PMF were of homogeneous radiodensity, sometimes rather ghost like in appearance. In the first reading shadows of diameter less than $3 \mathrm{~cm}$ were excluded from this group because of their small size, and were classified as type 2 PMF, but it became apparent after the first reading that some of the shadows less than $3 \mathrm{~cm}$ in diameter were more similar in general appearance to the type 1 homogeneous shadows, because of their irregular outline, than to the type 2 shadows. Accordingly on the second reading, irregular but homogeneous shadows were classified as type 1 whatever their size.

(2) The large opacities consisted of one or more homogeneous shadows markedly circular in outline, most of them (if multiple) of diameter less than 3 $\mathrm{cm}$. See note above for first reading.

(3) The large opacities were not homogeneous and appeared to consist of conglomerations of round shadows, each of diameter between 1 and $3 \mathrm{~cm}$.

(4) The large opacities were not homogeneous, and appeared to consist of conglomerations of small rounded opacities, $p$ or $q$ type.

(5) The large opacities were not homogeneous, and appeared to consist of conglomerations of small rounded opacities, $r$ type.

(6) The large opacities were not homogeneous, and appeared to consist of condensations of linear or streaky shadows.

Provision was also made for recording the presence of eggshell calcification of hilar nodes, but this appearance was not seen in this series of radiographs.

The measurement, estimation, and calculation of individual lifetime exposure to mixed respirable coalmine dust and quartz up to the time of follow up examination has been described previously, ${ }^{14}$ is and these represent each man's individual experience of dusty conditions integrated over his working lifetime.

Paired t statistics were calculated from the exposure of the individual cases and matched controls to mixed dust and to quartz dust. The statistical significance of these standardised mean differences were studied further using a logistic model ${ }^{16}$ in which the influences of both types of exposures were considered simultaneously.

\section{Results}

The frequencies of the differing types of PMF recorded were of similar orders at the two readings, 

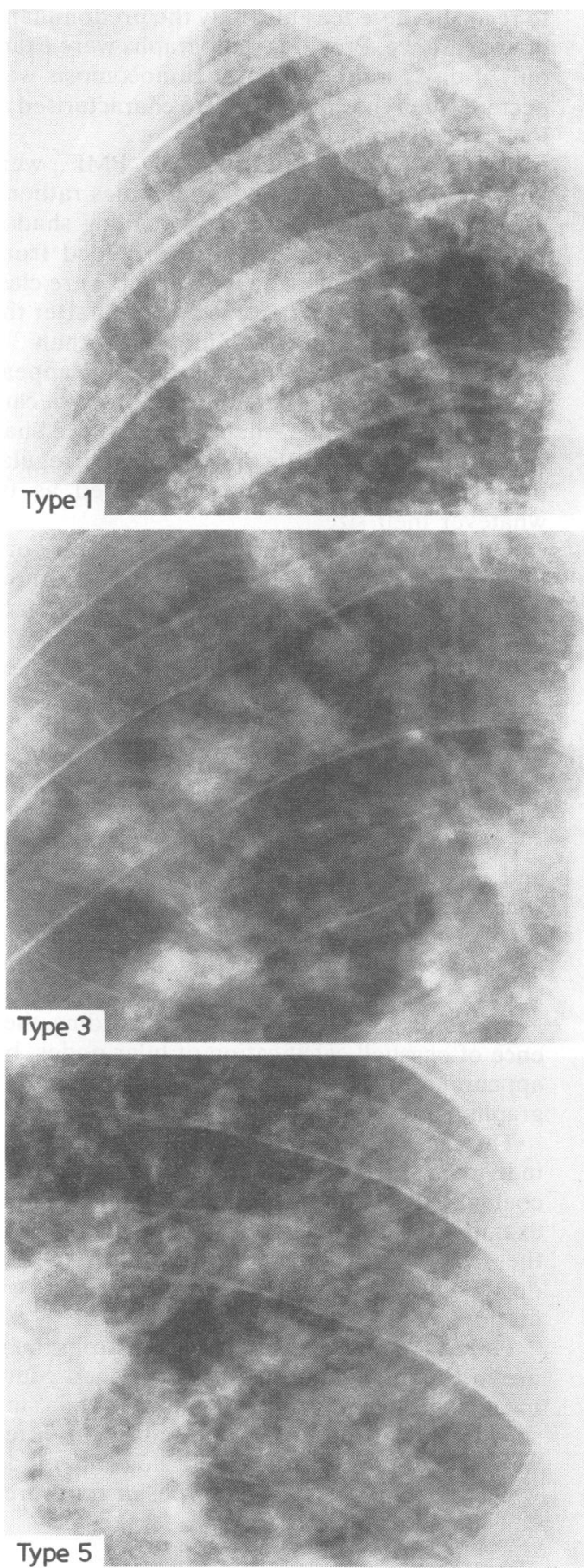
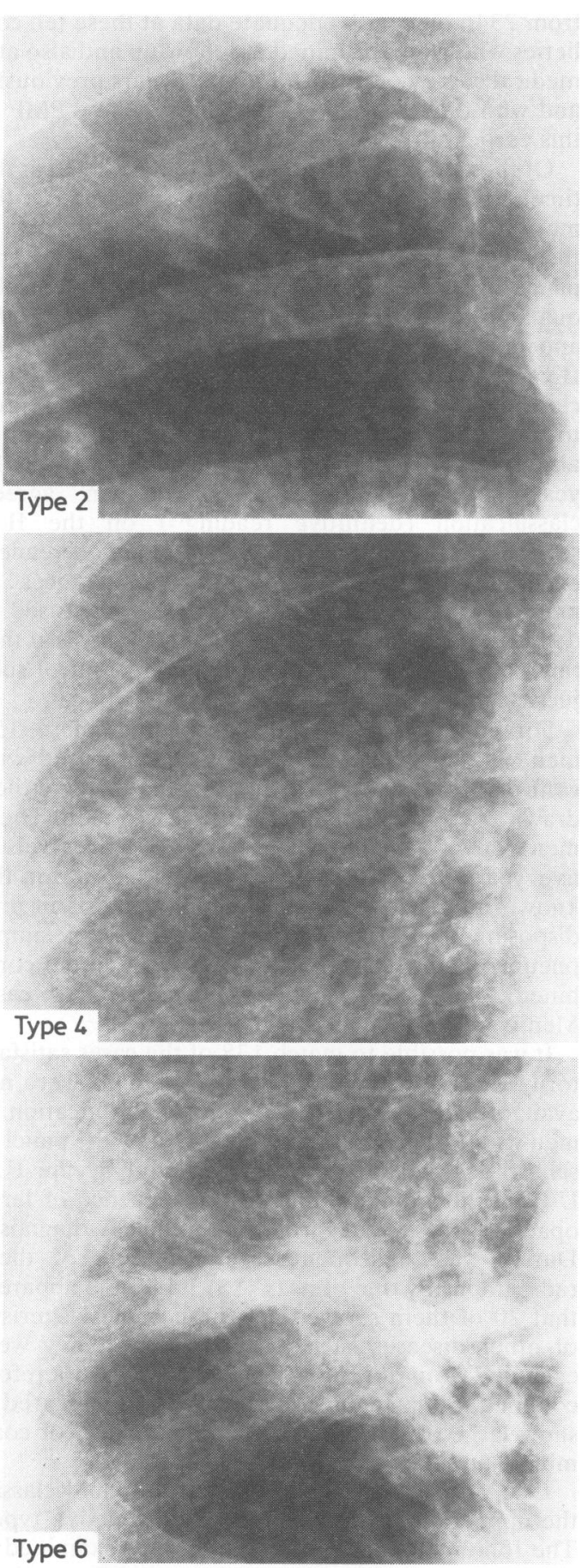

Type 6

무

Examples of radiographic types of progressive massive fibrosis of coalminers, types 1-6 (see text). 
Table 1 Classification of types of PMF in 112 radiographs. More than one type of $P M F$ could be recorded in a single radiograph

\begin{tabular}{llll}
\hline $\begin{array}{l}\text { Type of } \\
\text { PMF }\end{array}$ & $\begin{array}{l}\text { No classified } \\
\text { in furst } \\
\text { reading }\end{array}$ & $\begin{array}{l}\text { No classified } \\
\text { in second } \\
\text { reading }\end{array}$ & $\begin{array}{l}\text { No classified } \\
\text { in both } \\
\text { readings }\end{array}$ \\
\hline 1 & 55 & 64 & 53 \\
2 & 36 & 25 & 24 \\
3 & 6 & 7 & 5 \\
4 & 10 & 5 & 4 \\
5 & 8 & 7 & 4 \\
6 & 19 & 18 & 13 \\
\hline
\end{tabular}

and the numbers of radiographs in which the same type was recorded at both readings indicate reasonable reproducibility despite the intentional change in recording procedures between the two readings (table 1). Overall reproducibility was $92 \%$. The most common type was the large shadow or shadows of homogeneous radiodensity (type 1). Another common type was the markedly circular shadow or shadows. Other types were less frequent.

Good matching of 112 cases and 336 controls by age and by starting category of simple pneumoconiosis was achieved (table 2). The mean mixed dust exposures for both cases and controls appeared to be related to starting category of simple pneumoconiosis, and the mean exposure was consis- tently higher for cases than controls within each starting category. On average, the 112 men with PMF had been exposed to $11 \%$ more mixed dust than the 336 controls, and the mean difference is unlikely to be due to chance $(t=2.9, p<0.01)$. The higher exposures for the PMF cases was evident also in five of the six overlapping subgroups defined in terms of type of PMF (table 3 ).

The mean quartz exposures for these groups of men are also shown in table 3 . Overall the men with PMF had been exposed to slightly more quartz than the controls, though this difference could have arisen by chance one time in ten, and may reflect the differences in exposure to mixed dust. The eight men with type 5 PMF (conglomerations of $r$ type small opacities), however, had been exposed to substantially more quartz, even though they had been exposed to slightly less mixed dust, than the corresponding 24 controls. Results similar to those shown in table 3 were obtained when considering exposures of men grouped according to types of PMF using the second radiographic readings.

The logistic analysis confirmed the significance of the difference in mean mixed dust exposures between all cases and controls, but it showed no statistically significant independent effect of quartz after allowing for differences in mixed dust exposures.

Table 2 Distributions of 112 PMF cases and 336 controls by initial category of simple pneumoconiosis with means (and standard deviations) of ages and exposures to dust up to follow up survey, about 11 years later

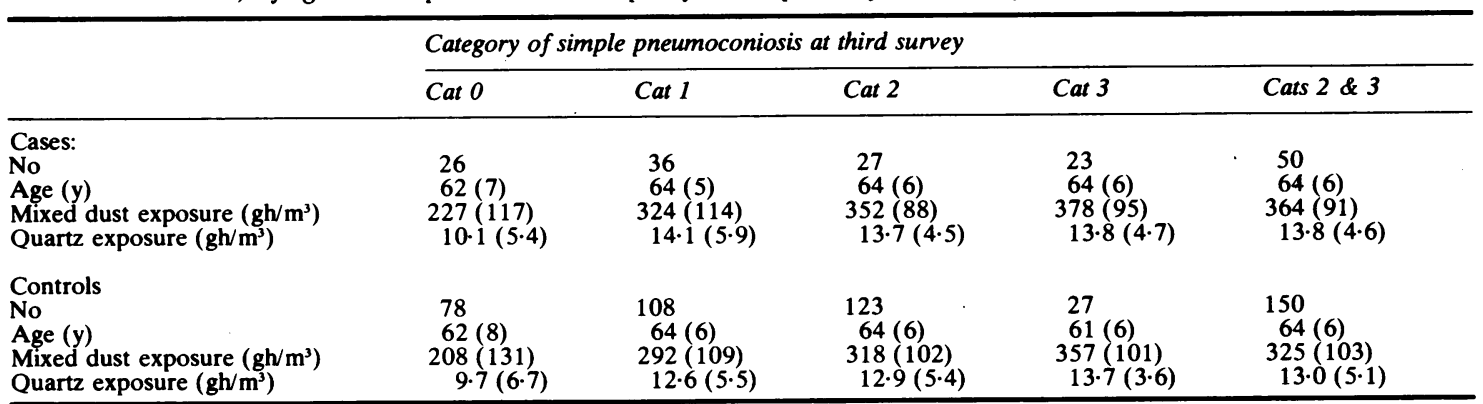

Table 3 Mean and (standard deviation) mixed dust exposures of 112 cases and 336 controls according to type of PMF, and standardised mean differences (cases-controls)

\begin{tabular}{|c|c|c|c|c|c|c|c|}
\hline \multirow{2}{*}{$\begin{array}{l}\text { Type of } \\
P M F\end{array}$} & \multirow{2}{*}{$\begin{array}{l}\text { No of } \\
\text { cases }\end{array}$} & \multicolumn{2}{|c|}{ Mixed dust exposures $\left(\mathrm{gh} / \mathrm{m}^{3}\right)$} & \multirow{2}{*}{$\begin{array}{l}\text { Standardised } \\
\text { mean } \\
\text { difference }(t)\end{array}$} & \multicolumn{2}{|c|}{ Quartz exposures $\left(g h / m^{3}\right)$} & \multirow{2}{*}{$\begin{array}{l}\text { Standardised } \\
\text { mean } \\
\text { difference }(t)\end{array}$} \\
\hline & & Cases & Controls & & Cases & Controls & \\
\hline $\begin{array}{l}1 \\
2 \\
3 \\
4 \\
5 \\
6 \\
\text { All }\end{array}$ & $\begin{array}{r}55 \\
36 \\
6 \\
10 \\
8 \\
19 \\
112\end{array}$ & $\begin{array}{l}340(112) \\
298(122) \\
372(179) \\
347(128) \\
289(81) \\
335(175) \\
320(117)\end{array}$ & $\begin{array}{l}299(72) \\
272(81) \\
295(90) \\
311(63) \\
300(63) \\
256(85) \\
287(79)\end{array}$ & $\begin{array}{c}2.7 \\
1.3 \\
0.8 \\
0.8 \\
-0.4 \\
1.9 \\
2.9^{*}\end{array}$ & $\begin{array}{l}13.6(5.4) \\
11.8(5.2) \\
12.1(4.2) \\
14.2(7.1) \\
16.1(4.3) \\
12.7(5.9) \\
13.0(5.4)\end{array}$ & $\begin{array}{l}12.3(3.1) \\
12.2(4.1) \\
10.4(4.7) \\
13.1(3.5) \\
11.4(3.6) \\
10.9(4.3) \\
12.1(3.7)\end{array}$ & $\begin{array}{c}1 \cdot 7 \\
-0.4 \\
0.5 \\
0.5 \\
3 \cdot 0^{*} \\
1 \cdot 1 \\
1 \cdot 7\end{array}$ \\
\hline
\end{tabular}

${ }^{*} \mathrm{p}<0.01$. 
The significance of the difference in mean quartz exposure for men with type 5 massive fibrosis was confirmed, and there was no significant difference in their mixed dust exposure.

Four men were classified as having type 5 PMF on both readings, and another seven men on one reading only. The mean quartz exposure for these 11 men was $15 \cdot 1 \mathrm{gh} / \mathrm{m}^{3}$ (SD 5.3), significantly higher than the corresponding controls $\left(11.5 \mathrm{gh} / \mathrm{m}^{3}, \mathrm{SD}\right.$ $3.9, p<0.05)$. The mean quartz exposure for the four men so classified on both readings was much higher than that for the corresponding controls $\left(19 \cdot 1 \mathrm{gh} / \mathrm{m}^{3}\right.$, SD $3 \cdot 0$, compared with $11 \cdot 1$, SD $2 \cdot 4$ $\left.\mathrm{gh} / \mathrm{m}^{3}, \mathrm{p}<0 \cdot 01\right)$. Five of these $11 \mathrm{men}$ had worked at only one of the 10 collieries $(p<0.02)$ (referred to elsewhere ${ }^{17}$ as colliery $\mathrm{X}$ ), where the respirable dust was known to have contained a relatively high proportion of quartz.

\section{Discussion}

This preliminary study has shown that classification of types of progressive massive fibrosis by radiographic appearance can be reproducible, and that such a classification may be useful in investigating the causes of the massive fibrosis of coalminers.

The classification described here is based on one reader's recognition of different patterns of large opacities in the chest radiographs. The mental process of pattern recognition would not necessarily be similar for other readers, and an examination of the classification and its use by other readers is planned, together with a comparison between radiographic appearances and pathology and a study of the changes in these appearances over an interval.

The two commonest types of massive fibrosis recorded in this group of men were the large homogeneous opacity, and the markedly rounded opacity. The markedly rounded opacities, whether separate or in conglomerate form, may in some men have been the result of Caplan's syndrome, ${ }^{18}$ whereas condensations of linear shadows could describe some non-occupational lung diseases, even though efforts were made to exclude such cases so far as possible. The type consisting of conglomerations of small rounded opacities of $r$ type which was here found to be related to quartz exposure might represent a type of coal pneumoconiosis generally characteristic of a response to coalmine dust with a high quartz content. Some coalminers suffering from unusually rapid progression of simple pneumoconiosis in response to high quartz exposures have been reported to show ${ }^{19}$ in the early stages of the disease dense, well defined, rounded opacities of $q$ or $r$ type (which in many cases become indistinguishable after further progression of the disease).
These opacities and the large opacities consisting of conglomerates of $r$ opacities seen in the present study, might possibly correspond to the silicotic type of nodule described in pathological studies of coalworkers' lungs. ${ }^{4-6}$ Further studies may determine whether recognition of this appearance can be useful clinically in identifying coalminers in whom respirable quartz dust has made an important contribution to the pneumoconiosis.

Our study confirms that despite considerable-individual variation, the magnitude of mixed respirable dust exposure is a major factor contributing to the incidence of PMF, ${ }^{1}$ and that the exposures of men with PMF are on average greater than those of men who develop only simple pneumoconiosis. ${ }^{20}$

Recent evidence has indicated that massive fibrosis associated with rapid progression of simple pneumoconiosis is related to high proportions of quartz in the mixed dust exposure, ${ }^{3}$ and we now suggest that one relatively infrequent type of massive fibrosis is related to the cumulative mass of respirable quartz in the exposure at the coal face.

We gratefully acknowledge the help of many colleagues in the Institute of Occupational Medicine.

The work was supported by the National Coal Board of the United Kingdom, and was partly based on records obtained during a follow up study of miners and ex-miners, supported by the Commission of the European Communities, CEC Contract 7246-16/8/002.

\section{References}

' McLintock JS, Rae S, Jacobsen M. The attack rate of progressive massive fibrosis in British coalminers. In: Walton WH, ed. Inhaled particles III. Vol. 2. Old Woking: Unwin Bros, 1971:933-52.

${ }^{2}$ Cochrane AL. The attack rate of progressive fibrosis. $\mathrm{Br} \mathrm{J}$ Ind Med 1962;19:52-64.

${ }^{3}$ Jacobsen M, Maclaren WM. Unusual pulmonary observations and exposure to coalmine dust: a case-control study. In: Walton WH, ed. Inhaled particles V. Oxford: Pergamon Press, 1982:753-65.

4 Gough J. Pneumoconiosis in coal trimmers. Journal of Pathology and Bacteriology 1940;51:277-85.

${ }^{5}$ Belt TH, Ferris AA. Pathological report. In: Medical research Council. Chronic pulmonary disease in South Wales coalminers. I. Medical studies. London: HMSO, 1942:203-22. (MRC special report series No 243.)

- Ruckley VA, Chapman JS, Collings PL, et al. Final report on CEC contract 7246-15/8/001. Autopsy studies of coalminers' lungs Phase II. Edinburgh: Institute of Occupational Medicine, 1981. (Institute of Occupational Medicine report No TM/81/18.)

${ }^{7}$ King EJ, Maguire BA, Nagelschmidt G. Further studies of the 
dust in lungs of coalminers. $\mathrm{Br} J$ Ind Med 1956;13:9-23.

${ }^{8}$ Faulds JS, King EJ, Nagelschmidt G. The dust content of the lungs of coalworkers from Cumberland. $\mathrm{Br} \mathrm{J}$ Ind Med 1959; 16:43-50.

${ }^{9}$ Spink R, Nagelschmidt G. Dust and fibrosis in the lungs of coalworkers from the Wigan area of Lancashire. $\mathrm{Br} J$ Ind Med 1963;20:118-23.

${ }^{10}$ Copland L, Burns I, Jacobsen M. Classification of chest radiographs for epidemiological purposes by people not experienced in the radiology of pneumoconiosis. $\mathrm{Br} \mathrm{J}$ Ind $\mathrm{Med}$ 1981;38:254-61.

"International Labour Office. ILO U/C international classification of radiographs of the pneumoconiosis, 1971. Geneva: ILO, 1972. (Occupational Safety and Health Series No 22.)

12 Jacobsen M, Burns J, Attfield MD. Smoking and coalworkers simple pneumoconiosis. In: Walton WH, ed. Inhaled particles IV. Vol 2. Oxford: Pergamon Press, 1977:759-72, section 3.2

${ }^{13}$ International Labour Office. Meeting of experts on the international classification of radiographs of the pneumoconioses. Occupational Safety and Health 1959;9:2-8.

${ }^{14}$ Hurley JF, Burns J, Copland L, Dodgson J, Jacobsen M. Coal- workers' simple pneumoconiosis and exposure to dust at 10 British coalmines. Br J Ind Med 1982;39:120-7.

is Dodgson J, Hadden GG, Jones CO, Walton WH. Characteristics of the airborne dust in British coalmines. In: Walton WH, ed. Inhaled particles III. Vol 2. Old Woking: Unwin Bros, 1971:757-82.

${ }^{16}$ Thomas DC. General relative-risk models for survival time and matched case-control analysis. Biometrics 1981;37:673-86

17 Walton WH, Dodgson J, Hadden GG, Jacobsen M. The effect of quartz and other non-coal dusts in coalworkers' pneumoconiosis. Part I: Epidemiological studies. In: Walton WH, ed. Inhaled particles IV. Vol 2. Oxford: Pergamon Press 1977:669-90.

18 Caplan A. Certain unusual radiological appearances in the chest of coalminers suffering from rheumatoid arthritis. Thorax 1953;8:29-37.

${ }^{19}$ Seaton A, Dick JA, Dodgson J, Jacobsen M. Quartz and pneumoconiosis in coalminers. Lancet 1981;ii:1271-5.

20 Jacobsen M. Dust exposure, lung diseases and coalminers' mortality. Edinburgh: University of Edinburgh, 1976:164. (PhD thesis.) 